\title{
Post-irradiation surgery for bronchogenic carcinoma
}

\author{
LAWRENCE SMITH AND T. PARNSINGHA \\ From Auckland Hospital, Park Road, Auckland C.3, New Zealand
}

In an attempt to improve both the resectability and survival rates for bronchogenic carcinoma, pre-operative supervoltage radiotherapy was introduced in 1961 and continued for a period of three years. Patients with either a histological or cytological diagnosis were given a tumour dose of 4,500 r over six weeks and then a two-month period elapsed before surgery. A follow-up of cases treated during the period revealed a five-year survival rate of $15.7 \%$. This rate is low when compared with the results achieved at this hospital with surgery alone. This finding is attributed to the harmful effects of radiotherapy which have led to a high bronchopleural fistula rate of $15.5 \%$. A single case of myocardial radionecrosis also occurred. No improvement is noted in the resectability rate. An overall assessment is that radiotherapy has provided no benefits but has in fact greatly increased both the morbidity and mortality rates.

Bronchogenic carcinoma remains the commonest neoplasm responsible for hospital admissions in New Zealand males. The number undergoing resection for carcinoma among cases referred to the Green Lane Hospital Chest Clinic remains at about $20-25 \%$. Recent papers have shown that the five-year survival rate after resection of bronchial carcinoma is about $25 \%$ (Belcher and Anderson, 1965 ; Goldman, 1965 ; Clagett, Allen, Payne, and Woolner, 1964 ; Bignall, Martin, and Smithers, 1967) and in some series it has been notably higher than this (Flavell, 1962). In an attempt to increase the resection rate, and following an optimistic report by Bloedorn and Cowley (1960), a programme of intensive supervoltage radiotherapy followed after two months by surgery was introduced as the treatment of choice at the Cardiothoracic Surgical Unit, Green Lane Hospital, for all operable cases of bronchogenic carcinoma from 1961 to 1963 inclusive. A histological or cytological diagnosis was established before beginning supervoltage radiotherapy.

There is good experimental evidence to suggest that irradiation helps to prevent the growth of disseminated cancer cells (Feder and Blair, 1964 ; Hoye and Smith, 1961). It might be expected to cut down the incidence of metastases arising locally or distally as a result of the operation. A high rate of bronchopleural fistulae following post-irradiation surgery had previously been reported by Bromley and Szur (1955), and this was acknowledged as a possible limiting factor to this combined therapy.

\section{SELECTION}

The majority of cases seen at the chest clinic were assessed as being inoperable. Another group of cases originally considered operable developed signs of inoperability in the course of treatment. The factors determining inoperability included the presence of distant metastases, age over 70 years, a poor respiratory reserve, a serious associated illness, a positive scalene node biopsy, a phrenic nerve palsy, brachial plexus lesions or chest wall involvement. The presence of enlarged mediastinal lymph nodes seen on a barium swallow or at exploratory thoracotomy did not contraindicate an attempt at post-irradiation resection.

If these inoperable patients are excluded the remaining patients fall into three groups:

GROUP A These patients received supervoltage radiotherapy followed by surgery two months later.

GROUP B These patients had no pre-operative histological diagnosis. If at exploratory thoracotomy they were regarded as particularly suitable for a primary resection this was performed.

GROUP C At exploratory thoracotomy these patients were regarded as inoperable.

\section{METHOD}

An estimated tumour dose of 4,500 $r$ was delivered by daily fractions over four weeks, using supervoltage therapy (4 MeV). The fields included the primary tumour and the important lymph drainage areas. An interval of two months elapsed until resection. Whenever possible a lobectomy was performed in preference to pneumonectomy. The ipsilateral media- 
T A B L E I

(a) TOTAL SURGICAL EXPERIENCE 1961-63 INCLUSIVE

\begin{tabular}{|c|c|c|c|c|c|c|}
\hline & \multirow{2}{*}{ No. } & \multirow{2}{*}{$\begin{array}{l}\text { Operative } \\
\text { Mortality }\end{array}$} & \multirow{2}{*}{ Pneumonectomy } & \multirow{2}{*}{ Lobectomy } & \multicolumn{2}{|c|}{ Survival } \\
\hline & & & & & 3-year & 5-year \\
\hline $\begin{array}{l}\text { Group A } \\
\quad \text { Pre-operative radiotherapy } \\
\quad \text { and excision } \ldots \\
\text { Group B }\end{array}$ & 58 & 9 & 44 & 14 & $(12 \cdot 1 \%)$ & $\left(\begin{array}{c}7 \\
(12 \cdot 1 \%\end{array}\right.$ \\
\hline $\begin{array}{l}\text { Excision only } \\
\text { Group C } \\
\text { Exploratory thoracotomy } \\
\text { and post-operative radio- } \\
\text { therapy .. }\end{array}$ & 13 & 1 & 5 & 7 & $\begin{array}{c}4 \\
(32.6 \%)\end{array}$ & $(23 \%)$ \\
\hline
\end{tabular}

(b) PULMONARY RESECTION 1957-59 INCLUSIVE

\begin{tabular}{l|c|c|c|c|c|c|c|}
\hline & No. & $\begin{array}{l}\text { Operative } \\
\text { Mortality }\end{array}$ & Pneumonectomy & Lobectomy & $\frac{2}{3 \text {-year }}$ & Survival \\
\hline $\begin{array}{c}\text { Resection with or without post- } \\
\text { operative radiotherapy }\end{array}$ & 81 & 5 & 63 & 18 & $\begin{array}{c}21 \\
(26 \%)\end{array}$ \\
\hline
\end{tabular}

stinal lymph nodes were excised and, when necessary, an intrapericardial pneumonectomy was performed. The bronchus stump was closed with interrupted silk sutures and buried whenever possible beneath a pleural flap.

\section{RESULTS}

The results of the 71 patients who had a pulmonary resection (groups $\mathbf{A}$ and $\mathbf{B}$ ) are summarized in Table I. The 20 patients who had an inoperable lesion at an exploratory thoracotomy (group C) are included in this table. Patients who died prior to their discharge from hospital are regarded as operative deaths.

In the post-irradiation surgical group (group A) there were nine hospital deaths. Four of these were directly attributable to bronchopleural fistulae, two were due to massive pulmonary embolism, and one each to cardiac arrhythmia, pneumonia, and myocardial radionecrosis.

A total of nine (15.5\%) group A patients developed bronchopleural fistulae. All of these patients eventually died, usually after a very unpleasant illness. Usually the fistulae occurred before the fourth week, but on occasions the onset was delayed several months. Four of these nine patients had proved concomitant metastatic disease. No bronchopleural fistulae occurred in the non-irradiated surgical group.

Radionecrosis of the myocardium, leading to fatal operative haemorrhage, occurred once; this case has been reported elsewhere (Windsor, 1963). Sudden deaths of presumed cardiac origin occurred in six other patients, but there is no evidence to establish any relationship with thg supervoltage therapy.

The supervoltage therapy made tissues thicke than normal during the hilar dissection but the did not make the operation more difficult. resectability rate of $79 \%$ was achieved among the cases coming to surgery.

The 58 post-irradiation surgical cases (Table II) had their tumours classified histologically into three main categories: (1) squamous; (2) un differentiated (large and small cell); and ( 39 adenocarcinoma, including the alveolar-cell type

T A B L E I I

(a) HISTOLOGY OF POST-IRRADIATION SURGICAL SPECIMENS

\begin{tabular}{|c|c|c|c|c|c|c|}
\hline & & & & \multirow{2}{*}{ Total } & \multicolumn{2}{|c|}{ Survival } \\
\hline & & & & & 3-year & 5 -yea \\
\hline $\begin{array}{l}\text { Squamous... } \\
\text { Undifferentiated }\end{array}$ & $\cdots$ & $\cdots$ & $\cdots$ & 41 & 6 & 6 \\
\hline Small cell & $\cdots$ & $\cdots$ & . & 10 & 1 & 1 \\
\hline Large cell & . & . & $\ldots$ & 5 & 0 & 0 \\
\hline Adenocarcinoma . & $\cdots$ & $\cdots$ & $\cdots$ & 2 & 0 & 0 \\
\hline Total . . & . & . & . & 58 & 7 & 7 \\
\hline
\end{tabular}

(b) HISTOLOGY OF PULMONARY RESECTION GROU 1957-59 INCLUSIVE

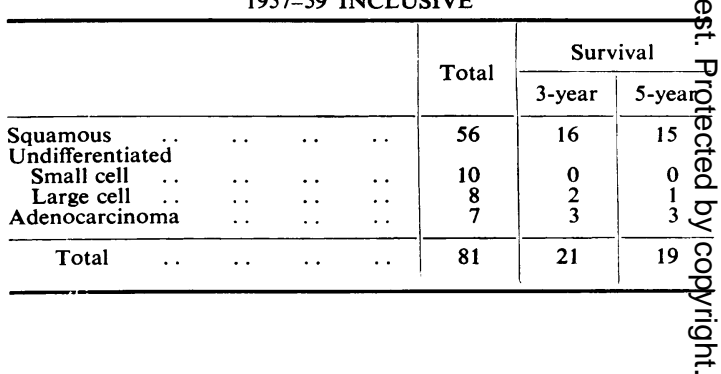


(Reid and Carr, 1961). Two tumours were classified by cytology alone.

Histological examination revealed that in 13 of the 58 irradiated surgical specimens there were no viable tumour cells visible in either the lung or lymph nodes. However, only three of these 13 cases that had been 'sterilized' by radiotherapy survived three years.

In order to obtain a comparison with a group of patients who received no pre-operative radiotherapy a study was made of patients operated upon for lung carcinoma over the three-year period, 1957-59. During this period 81 patients had pulmonary resections (Table I) and a resectability rate of $75 \%$ was achieved. There were five post-operative deaths, which included the only case of bronchopleural fistula in the series, an overall incidence therefore of $1.6 \%$.

Two of the patients remain untraced and are classified as late deaths. There have been 21 (26\%) three-year survivals and $19(23.5 \%)$ fiveyear survivals. The ratio of pneumonectomies to lobectomies performed in this earlier group was higher than in the post-irradiation group.

The histology of the resected specimens (Table II) was similar except for a slightly higher incidence of adenocarcinoma.

\section{DISCUSSION}

Delaying surgery for two months after supervoltage radiotherapy, as recommended by Bloedorn and Cowley (1960), has in this series of 58 cases (group A) produced a three- and five-year survival rate of $12 \cdot 1 \%$. The overall five-year survival rate of group A and group B cases is $15.7 \%$. Though the series are not exactly comparable, Linberg, Cowley, Bloedorn, and Wizenberg (1965), in a follow-up of 82 post-irradiation resections, reported a $17 \%$ three-year survival rate. These figures are lower than the three- and even fiveyear survival rates for surgery alone achieved at this hospital, and also reported in other series. No important difference in the resectability rate has been achieved with radiotherapy. These results and the later experience of Linberg et al. (1965) have shown that better results are not achieved by this combined therapy. The results are disappointing and are similar to those originally reported by Bromley and Szur (1955).

The number of resections performed during the period of pre-operative irradiation was less than when this therapy was not used. This discrepancy can be explained by a number of cases that developed metastases or other inoperable features during the four months that elapsed between the beginning of radiotherapy and the date when surgery was planned.

A bronchopleural fistula rate of $15.5 \%$ among the irradiated group is high and compares unfavourably with a $1.5 \%$ incidence in a large group of cases reported by Flavell (1962) using surgery alone and the $1.6 \%$ incidence obtained in this hospital before the introduction of pre-operative radiotherapy. These results are in accord with the high rate of empyema and bronchopleural fistula of $27 \%$ and $25.6 \%$ reported respectively by Bromley and Szur (1955) and Linberg et al. (1965). This high incidence is attributed to impaired tissue healing and lowered tissue resistance resulting from radiotherapy. A single case of radiation damage to the myocardium was encountered, but this would seem an uncommon complication.

Paulson (1968) has established that preoperative irradiation is justified for bronchogenic carcinoma of the 'superior pulmonary sulcus' producing Pancoast's syndrome. He has achieved a $35 \%$ five-year survival rate in a group which in the past has generally been considered hopeless.

There is little doubt that supervoltage radiotherapy has a profound effect on the primary tumour and the hilar and mediastinal lymph node metastases. Twenty-five per cent of the lung specimens and lymph nodes had been 'sterilized' by radiotherapy, and even higher figures have been reported by Bromley and Szur (1955) and Bloedorn and Cowley (1960). The three-year survival rate of the 'sterilized' cases has, however, shown no significant improvement. Baker, Cowley, and Linberg (1963) reported on 17 cases of 'locally cured' bronchogenic carcinoma with only one survivor after three and a half years.

The prognosis of patients with small and large cell tumours was worse than that of those with squamous type tumours, but the numbers are too small to draw conclusions. According to Siddons (1962), the five-year survival rates are not sufficiently different to single out any one histological type for separate consideration in therapy.

\section{CONCLUSIONS}

Seventy-one cases of bronchogenic carcinoma treated by surgical excision are discussed, 58 of them having had pre-operative radiotherapy and delayed surgery.

A comparison is made with 81 patients who had surgical excision prior to the introduction of preoperative radiotherapy.

Thirteen cases had been 'sterilized' by supervoltage radiotherapy, but the prognosis remained poor. 
A low three-year survival of $15.7 \%$ is reported.

Post-irradiation complications included one case of myocardial radionecrosis and nine cases $(15.5 \%)$ of bronchopleural fistula.

The combined treatment of supervoltage therapy plus surgery has produced worse results than might have been expected from surgery alone, and this is believed to be due to the complications of radiotherapy.

We wish to thank Sir Douglas Robb for initially suggesting the survey and Mr. B. G. Barratt-Boyes and Mr. D. S. Cole for their criticisms in the preparation of this paper.

\section{REFERENCES}

Baker, N. H., Cowley, R. A., and Linberg, E. (1963). A follow-up in patients with bronchogenic carcinoma "locally cured" by preoperative irradiation. J. thorac. cardiovasc. Surg., 46, 298.

Belcher, J. R., and Anderson, R. (1965). Surgical treatment of carcinoma of the bronchus. Brit. med. J., 1, 948.

Bignall, J. R., Martin, M., and Smithers, D. W. (1967). Survival in 6086 cases of bronchial carcinoma. Lancet, $1,1067$.
Bloedorn, F. G., and Cowley, R. A. (1960). Irradiation and surger in the treatment of bronchogenic carcinoma. Surg. Gynec. Obstet 111,141 .

Bromley, L. L., and Szur, L. (1955). Combined radiotherapy an resection for carcinoma of the bronchus. Experiences with 68 patients. Lancet, $2,937$.

Clagett, O. T., Allen, T. H., Payne, W. S., and Woolner, L. B. (1964 The surgical treatment of pulmonary neoplasms: a 10-yea experience. J. thorac. cardiovasc. Surg., 48, 391.

Feder, B. H., and Blair, P. B. (1964). Preoperative irradiations evaluation by a simple experimental model. Radiology, 83, $11 \mathrm{~L}$

Flavell, G. (1962). Conservatism in surgical treatment of bronchia $\Phi$ carcinoma; a review of 826 personal operations. Brit. med. J., 284

Goldman, K. P. (1965). Histology of lung cancer in relation to prog nosis. Thorax, 20, 298.

Hoye, R. C., and Smith, R. R. (1961). The effectiveness of smax amounts of pre-operative irradiation in preventing the growth of tumor cells disseminated at surgery. An experimental stud Cancer (Philad.), 14, 284

Linberg, E. J., Cowley, R. A., Bloedorn, F., and Wizenberg, M. A (1965). Bronchogenic carcinoma: further experience with pre्ध operative irradiation. Ann. thorac. Surg., 1, 371.

Paulson, D. L. (1968). A philosophy of treatment for bronchogenio carcinoma. Ibid., 5, 289.

Reid, J. D., and Carr, A. H. (1961). The validity and value of histelogical and cytological classifications of lung cancer. Cancer. (Philad.), 14, 673.

Siddons, A. H. M. (1962). Cell type in the choices of cases of carcinor of the bronchus for surgery. Thorax, 17, 308 . Windsor, R. (1963). Cardiac damage after radiotherapy. Brit. med. $\overrightarrow{\mathscr{D}}$
1, 382. 